University of New Hampshire

University of New Hampshire Scholars' Repository

$12-10-2015$

\title{
Campus Community Readiness to Engage Measure: Its Utility for Campus Violence Prevention Initiatives-Preliminary Psychometrics
}

\author{
Katie Edwards \\ University of New Hampshire - Main Campus, katie.edwards@unh.edu \\ Mary M. Moynihan \\ University of New Hampshire - Main Campus, Mary.Moynihan@unh.edu \\ Kara Anne Rodenhizer-Stampfli \\ University of New Hampshire - Main Campus \\ Jennifer M. Demers \\ University of New Hampshire - Main Campus \\ Victoria Banyard \\ University of New Hampshire, Victoria.banyard@unh.edu
}

Follow this and additional works at: https://scholars.unh.edu/pirc

Part of the Community-Based Research Commons, Domestic and Intimate Partner Violence Commons, and the Social Psychology Commons

\section{Recommended Citation}

Edwards Katie M., Moynihan Mary M., Rodenhizer-Stämpfli Kara Anne, Demers Jennifer M., and Banyard Victoria L.. Violence and Gender. December 2015, 2(4): 214-224. doi:10.1089/vio.2015.0028.

This Article is brought to you for free and open access by the Prevention Innovations Research Center (PIRC) at University of New Hampshire Scholars' Repository. It has been accepted for inclusion in Peer-Reviewed and Other Publications by an authorized administrator of University of New Hampshire Scholars' Repository. For more information, please contact Scholarly.Communication@unh.edu. 


\title{
Campus Community Readiness to Engage Measure: Its Utility for Campus Violence Prevention Initiatives-Preliminary Psychometrics
}

\author{
Katie M. Edwards, PhD, ${ }^{1,2,5}$ Mary M. Moynihan, $\mathrm{PhD},{ }^{2,3,5}$ Kara Anne Rodenhizer-Stämpfli, MA, ${ }^{1}$ \\ Jennifer M. Demers, MA, and Victoria L. Banyard, $\mathrm{PhD}^{1,4,5}$
}

\begin{abstract}
The researchers present preliminary psychometric information on a recently developed measure- the Campus Community Readiness to Engage Measure (CCREM) - which was developed as a tool for campuses to determine their readiness to address sexual assault (SA) and relationship abuse (RA). Participants were 353 community leaders and administrators at 131 colleges and universities across New England. Factor analytic results demonstrated that the CCREM had three factors for both SA and RA: denial (the campus community is unwilling to acknowledge that SA and RA are issues for the community), initiation (the campus community is beginning to create efforts to address SA and RA and some community members are involved), and sustainability (the campus has high levels of engagement from community members and longstanding efforts to address SA and RA). Whereas there was fair to moderate agreement among raters within the same community on the sustainability and initiation subscales, there was poor to fair agreement among raters within the same community on the denial subscale. Although additional measurement development research is needed, preliminary data suggest that the CCREM may be useful to campus communities in helping to initiate prevention initiatives and implement services related to SA and RA.
\end{abstract}

\section{Introduction}

$\mathbf{S}^{\mathrm{s}}$ EXUAL assault (SA; a continuum of behaviors including unwanted sexual contact, sexual coercion, and attempted and completed rape) and relationship abuse (RA; sexual, psychological, and/or physical violence that occurs within the context of an intimate relationship) are pervasive problems on college ${ }^{1}$ campuses (Fisher et al. 2000; Kilpatrick et al. 2007; Krebs et al. 2007; Edwards et al. 2015). Although researchers, advocates, and administrators are recognizing the critical role that campus communities play in preventing and responding to SA and RA among their students (e.g., Casey and Lindhorst 2009; Moynihan et al. 2015), variability exists in how campuses develop, implement, and evaluate prevention and intervention efforts relating to these issues (Karjane et al. 2002). To date,

\footnotetext{
${ }^{1}$ Although "college" and "university" are used interchangeably throughout the article, for consistency we primarily use "university" to be inclusive of both universities and colleges.
}

however, there is no quantitative measure that captures the extent to which campus communities are engaged around issues of SA and RA.

The creation of a measure to assess campus readiness to engage around issues of SA and RA could be useful not only to researchers conducting campus climate research, but also for colleges and universities in determining their strengths and weaknesses in preventing and responding to SA and RA and measuring the progress of their efforts over time. A readiness to engage measure is especially timely in light of various state and federal acts, policies, and initiatives (e.g., Violence Against Women Act, Title IX, Dear Colleagues Letter, Clery Act) requiring college administrators to do more to address SA and related forms of violence on their campuses. Moreover, the White House Task Force to Protect Students from Sexual Assault recently released a report that urged campuses to conduct local campus climate surveys to inform programs, policy, and prevention efforts (White House 2014). Although the White House report calls for the importance assessing community readiness to engage as part of broader climate survey procedures, to date there is no such measure. Thus, the purpose of the current study was

\footnotetext{
${ }^{1}$ Department of Psychology, ${ }^{2}$ Women's Studies Program, ${ }^{3}$ Justice Studies Program, ${ }^{4}$ Department of Justice Studies, and ${ }^{5}$ Prevention Innovations Research Center, University of New Hampshire, Durham, New Hampshire.
} 
to provide preliminary psychometric data on a quantitative measure assessing campus community readiness to engage around issues of SA and RA, grounded in the community readiness model (CRM) (Plested et al. 2006).

The CRM, theoretically derived from Prochaska and DiClemente's $(1983,1984)$ transtheoretical model, focuses on the degree to which the community is prepared to take action on the issue of interest (Plested et al. 2006). Rather than trying to implement a one-size-fits-all model for change, the CRM acknowledges the variability in readiness across communities so that change efforts can be appropriately tailored to meet communities' specific needs (Plested et al. 2006). The CRM consists of nine community levels of readiness that are assessed on six dimensions (Plested et al. 2006). The levels of readiness range from no awareness or identification that the issue is a problem (stage 1) to high level of community ownership, where there is detailed knowledge and awareness of the issue, sustained programs are in place to address the issue, and the efficacy of these efforts is routinely evaluated and adjusted as needed (stage 9) (for the complete list of all the stages of readiness, see Plested et al. 2006). The six dimensions of the CRM are community efforts (e.g., programs and policies); community knowledge of efforts (e.g., how aware are community members of current efforts related to the issue); leadership concern (e.g., to what extent are community leaders, such as policy makers or administration, concerned with the issue); community climate (e.g., community's attitude toward the issue); community knowledge of the issue (e.g., how much do community members know about the issue); and resources related to the issue (e.g., time, money, people, space) through qualitative interviews (Plested et al. 2006). Using the CRM, the original method for determining community readiness is through a series of qualitative interviews with community leaders and stakeholders that are scored in a way that determines stage of readiness (1-9) on the six different dimensions as well as an overall community readiness score (Plested et al. 2006).

Although the original CRM interview tool was developed in the mid-1990s to address substance abuse issues (Plested et al. 2006), the CRM interview tool has been used to address other social and behavioral health issues, including (but not limited to) childhood obesity (Findholt 2007), head injury (Stallones et al. 2008), HIV/AIDs (Jumper-Thurman et al. 2007), school dropout (Luna 2008), SA among adolescents (DeWalt 2009), and RA in a southern U.S. state (Brackley et al. 2003). For example, Brackley et al. (2003) described the use of the CRM interview tool to determine a southern community's readiness to prevent RA and develop targeted interventions to move the community to a higher stage of readiness to prevent RA. Further, in a conceptual article, Wasco and Zadnik (2013) described how the CRM interview tool could be applied to campus SA prevention work.

In addition to using the CRM interview tool to assess readiness for a number of social and behavioral health issues, researchers have attempted to create quantitative CRM survey tools as an alternative to the interview tool that can be timely and costly. Quantitative CRM survey tools have been adapted for issues such as child maltreatment prevention (Mikton et al. 2011, 2013), campus tobacco policy (Whipple et al. 2010), and substance abuse (see Raffle 2011 for a review). To date, however, there is no CRM survey tool for SA and RA. Such a tool could be used on campuses to describe their starting point for implementing responses to RA or SA. A self-administered CRM instrument could improve campus professionals' understanding of their campuses' current stage of readiness. For example, a campus with community members who have little awareness that SA is a problem for their local community might be best served with a climate survey to document the incidence and prevalence of SA and RA, as well as awareness campaigns and efforts to help community members identify the problem. By contrast, another campus may already have extensive knowledge of the problem and may even have a number of preliminary prevention and response efforts in place, but these efforts may be relatively unknown and not reach very many community members. This second campus requires a different set of strategies perhaps to better publicize activities or to evaluate their impact. In sum, an instrument such as the one proposed in the current study could serve as an indicator of how engagement, commitment, and activity of a campus to address SA or RA changed over time.

In developing the current measure, we relied heavily on the CRM interview tool questions and scoring anchors across the nine stages and six dimensions of readiness. We edited, tailored, and added items not in the CRM materials based on (1) our collective expertise on SA and RA campus climate issues; (2) feedback received from campus practitioners with expertise in SA and RA issues on college campuses; and (3) a comprehensive review of the scholarly literature focusing on the problems of SA and RA on campus (e.g., Karjane et al. 2002; California Campus Sexual Assault Task Force 2004; Lichty et al. 2008; Wasco and Zadnik 2013). Once the initial item pool was finalized, we administered the survey to college campus leaders and administrators across New England (U.S.) in order to obtain preliminary psychometric data (i.e., factor structure, reliability, and validity) on the measure, which we refer to as the Campus Community Readiness to Engage Measure (CCREM).

\section{Methods}

\section{Participants}

Participants consisted of 353 community leaders and administrators (women $=201$; men $=150$ ) at 131 universities across New England. Although 353 individuals started the survey, due to missing data and participants' indication that they did not have enough information to answer the questions, the sample sizes in the analyses ranged from 143 to 229. The age of the majority $(72.3 \%)$ of participants was between 31 and 60 years $(18-25=8.0 \% ; 26-30=7.4 \% ; 31-$ $40=18.9 \% ; \quad 41-50=21.7 \% ; \quad 51-60=31.7 \% ; \quad 61-$ $70=11.7 \% ; 71-80=0.6 \%$ ). Although these participants held a wide variety of positions at their respective universities, individuals holding the following 12 positions were actively targeted for participation: president, dean of students, residence life director, campus security/chief of police, student mental health services director, student health services director, student affairs administrator, student body president, women's center/crisis center director, student judiciary director, multicultural director/LGBTQ+ director, and athletic director. We selected these positions because 
individuals occupying them are typically involved in prevention and response efforts or are gatekeepers of SA and RA efforts. Respondents affiliated with the following offices: student and academic affairs, including the dean of students $(20.9 \%)$; health services $(17.4 \%)$; residence life (11.6\%); campus security $(7.8 \%)$; student judiciaries $(5.2 \%)$; athletics $(4.9 \%)$; religious and chaplain services (4.7\%); women's center/crisis center/Title IX (4.4\%); student body government $(2.9 \%)$; university president $(2.0 \%)$; diversity offices $(2.0 \%)$; a combination of the position mentioned previously $(5.8 \%)$; or a position that did not fit into any of these categories but, nonetheless, the person responding believed that he or she was in a position to do so (e.g.; professor who researches SA) (10.2\%). The length of time that participants had been members of their university ranged from less than 1 year to 50 years, with a mean of 10.6 years $(S D=9.10)$. Participants had been employed in or elected to their current positions for 7.24 years on average, with a range of less than 1 year to 37 years $(\mathrm{SD}=6.50)$.

\section{Procedure}

To conduct this study, we obtained a list of all universities in New England (U.S. Universities 2014). Universities offering only graduate studies, professional degrees, or online degrees were excluded. The final list consisted of 158 universities from the following states: Connecticut $(n=24)$, Maine, $(n=18)$, Massachusetts $(n=76)$, New Hampshire $(n=14)$, Rhode Island $(n=8)$, and Vermont $(n=18)$. We conducted all the research in compliance with the university's Institutional Review Board for the protection of human subjects in research.

In order to find the persons appropriate to ask to complete our study, we selected the 12 categories of positions of interest listed above and conducted an Internet search to find the applicable contacts at each school. After all available contact information was collected, a near-identical e-mail was sent out to each contact stating that we were "developing a measure to understand whether interpersonal violence is a problem for different college communities and how college campuses are addressing issues related to SA and relationship abuse on campuses" and inviting them to participate in a survey. They were informed that they had been chosen to participate based on their position at their university and were given the choice of completing the survey online via the link provided, via a mailed paper-andpencil survey, or via a phone interview.

Following the initial e-mailed invitation, we made a follow-up call and sent a corresponding e-mail to anyone whom had not yet responded. The e-mails consisted of the original invitation to participate, with the addition of a personalized paragraph indicating that we had not heard from them and would appreciate their participation in our study.

Recipients were told that, should they be unable to participate for any reason or believe that they were not the appropriate contact, we welcomed suggestions for someone in a similar position at their university whom we might contact instead. If there were any positions at their school that did not have associated contact information and had been marked for follow-up, additional language was added to the end of the e-mail, listing the missing positions and asking e-mail recipients to identify any individuals that they could who filled those missing positions. Upon reception of appropriate suggestions, we added the new contacts to our list and e-mailed an invitation.

Of all of the individuals initially e-mailed $(n=1,293)$, $27.3 \%(n=353)$ started the survey. Across all of the targeted universities $(n=158)$, at least one person from $82.9 \%$ $(n=131)$ of the institutions took the survey. On average, 2.60 individuals participated from a given university (range $=1-20, \mathrm{SD}=2.15$ ).

Recipients interested in participating by mail or phone were asked to call the researchers to make arrangements. Almost all participants (99\%) chose to take the online survey. Informed consent was obtained from all participants before their completion of the survey, and all participants received a debriefing form upon completion that provided them with resource and referral information. As an incentive to fill out the survey, potential participants were offered the chance to win one of three $\$ 100$ Visa gift cards.

\section{Measures}

Campus Community Readiness to Engage. The CCREM is the measure we developed for the study. The initial item pool $^{2}$ consisted of $55 \mathrm{SA}$ items and $55 \mathrm{RA}$ items. A number of items examined each of the six different domains (e.g., efforts, resources), and within each of the six domains, we created items that tapped into each of the nine stages of readiness (e.g., denial/resistance, high levels of community ownership), all consistent with the CRM and associated interview schedule and scoring guidelines (Plested et al., 2006). Response options for the items ranged from 1 (Does Not Describe My Campus Community) to 4 (Describes My Campus Community Very Well) with an "I do not know" option. Individuals who answered, "I do not know" were excluded from the analyses. Participants were provided with definitions of SA and RA modeled after Centers for Disease Control and Prevention (CDC) definitions of SA and intimate partner violence, respectively (Basile and Saltzman 2002).

SA and RA victim and perpetrator contact. As a possible correlate of perceptions of readiness, we asked four questions to determine the extent to which participants worked with victims and/or perpetrators of SA as well as victims and perpetrators of RA in the context of their work at their university. Response options ranged from 1 (Never) to 4 (Often).

SA and RA efforts. We asked 49 questions to determine the presence or absence of a number of SA and RA services (e.g., 24-hour campus hotline for SA, crisis intervention counselors for victims of RA), efforts (e.g., social marketing/campus community-wide media campaigns about SA, RA education workshops), and on-campus policies (e.g., disclosure of victim's rights in the adjudication process, campus policy about RA). Eighteen questions were specific

\footnotetext{
${ }^{2}$ Due to space limitations, we could not include the full item pool. Contact the first author for a copy of the initial item pool.
} 


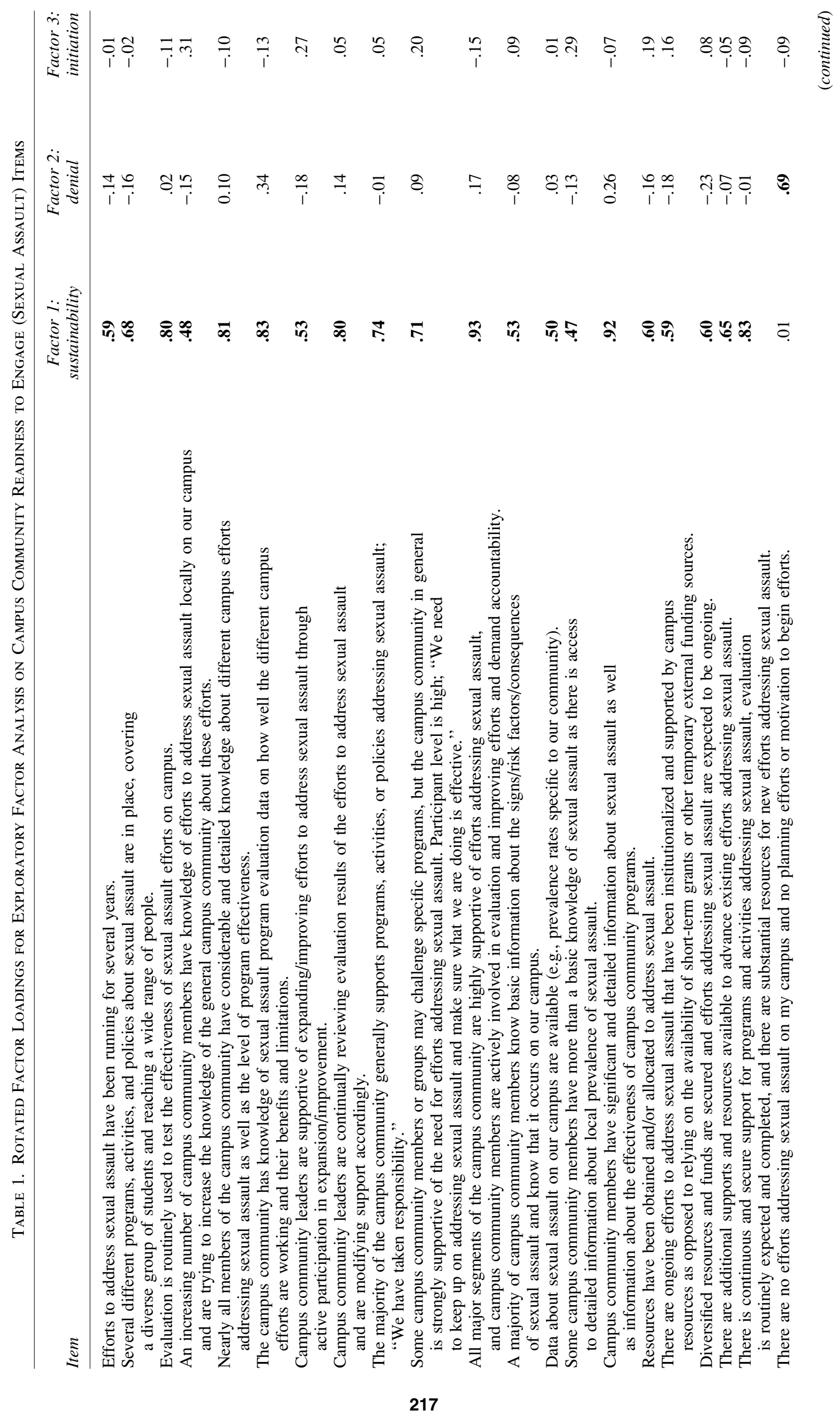




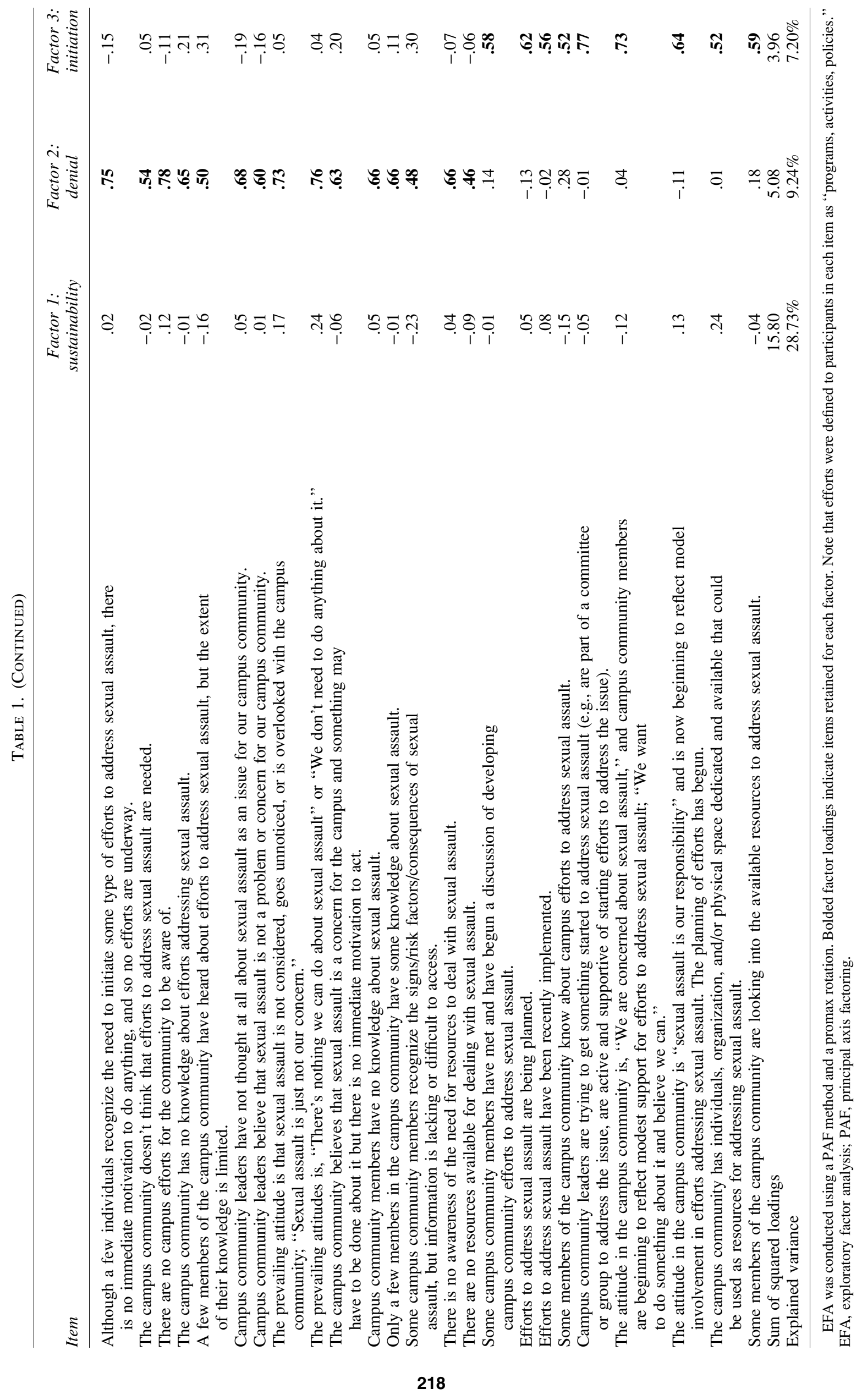




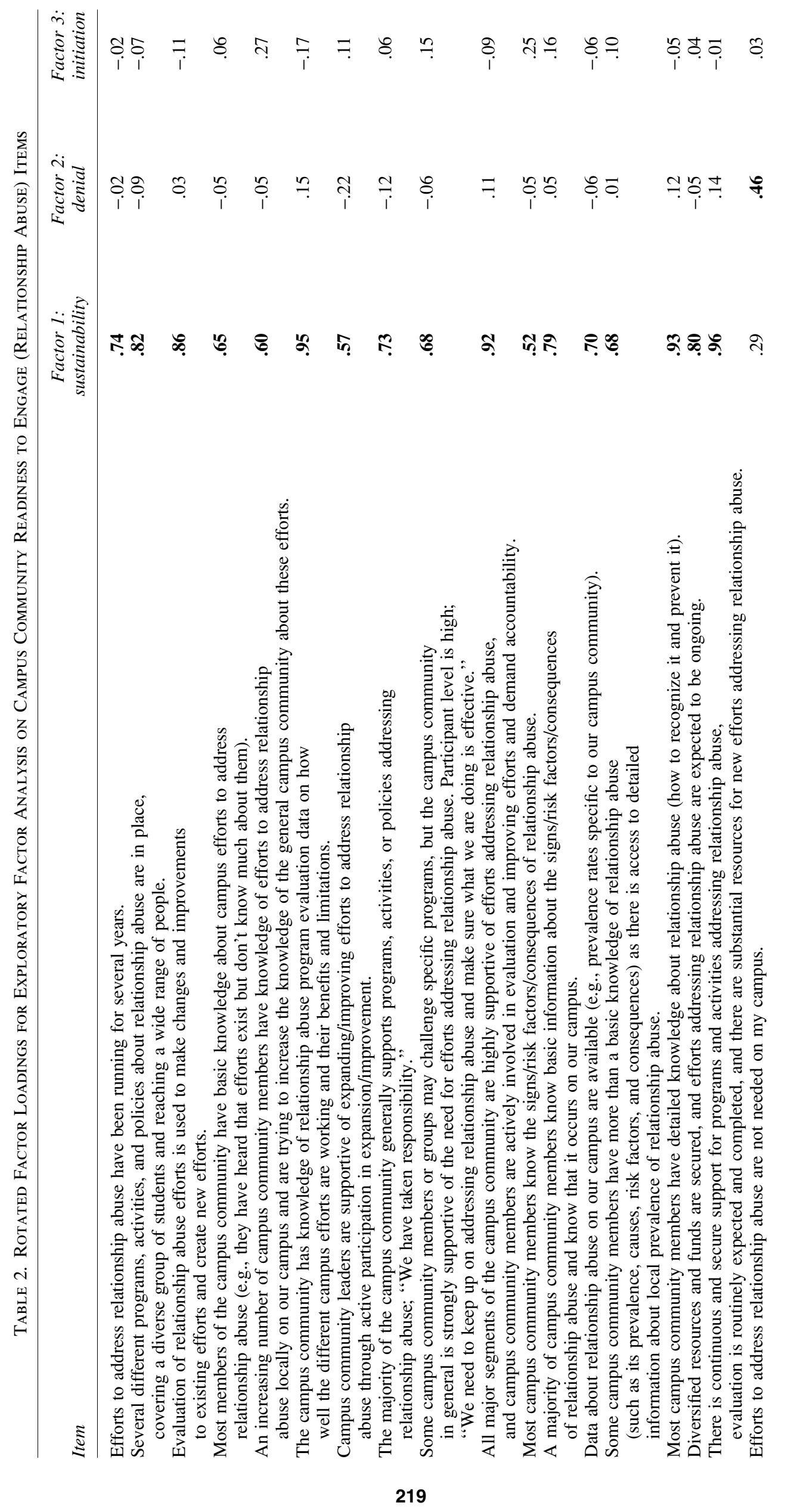




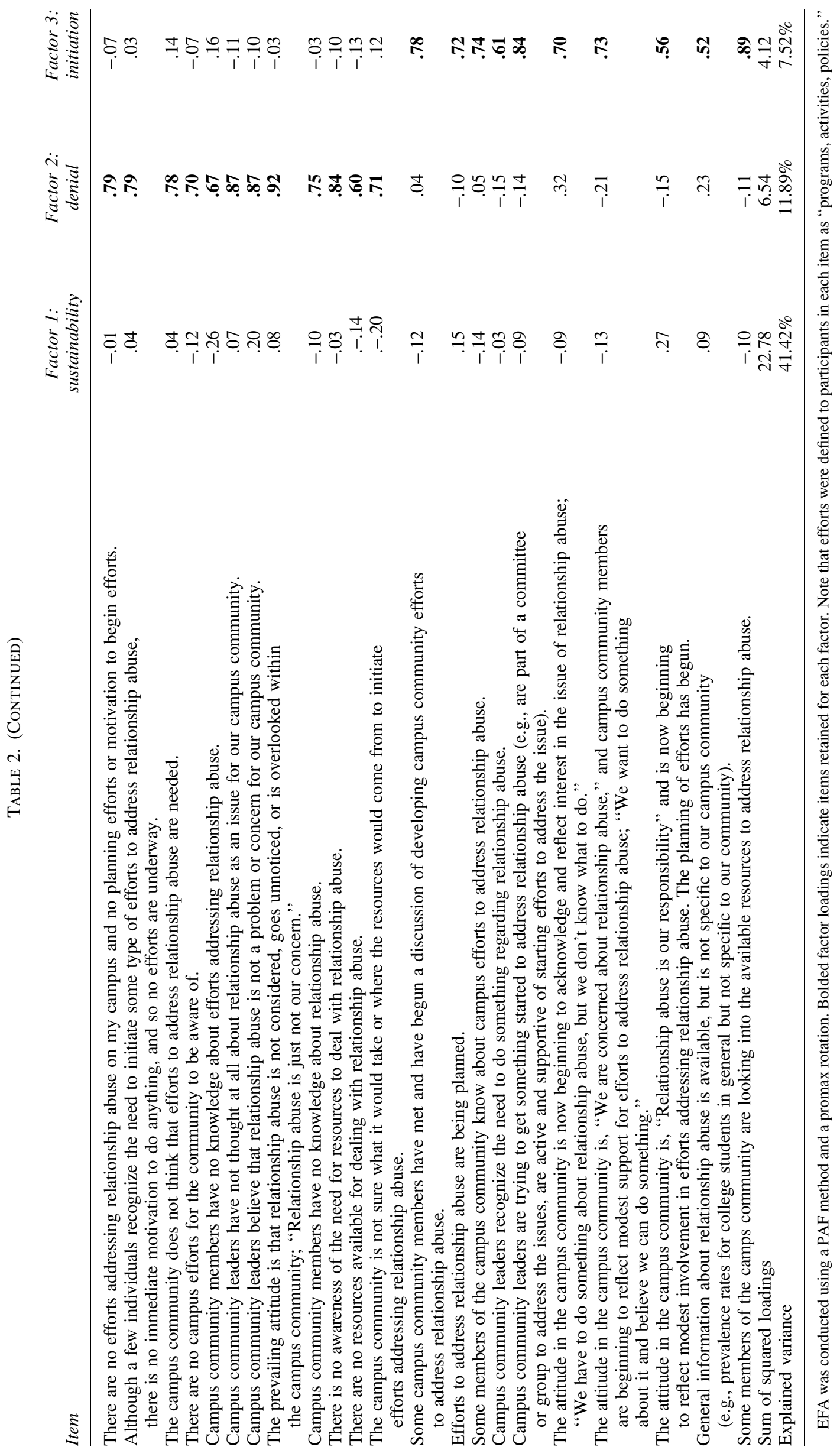


Table 3. Subscale Descriptive and Basic Inferential Statistics

\begin{tabular}{|c|c|c|c|c|c|c|c|c|c|c|}
\hline & $S A-$ sustain & $S A-$ denial & SA-initiation & $R A-$ sustain & $R A$-denial & $R A$-initiation & Mean & Range & $S D$ & $\begin{array}{c}\text { Cronbach } \\
\text { alpha }\end{array}$ \\
\hline SA-sustain & 1 & $-.58 * * *$ & .07 & $.84 * * *$ & $-.63 * * *$ & $.28 * *$ & 2.85 & $1.15-4.00$ & 0.66 & 0.946 \\
\hline SA-denial & & 1 & .11 & $-.44 * * *$ & $.70 * *$ & .01 & 1.42 & $1.00-3.38$ & 0.46 & 0.906 \\
\hline SA-initiation & & & 1 & -.01 & .03 & $.71 * * *$ & 2.92 & $1.00-4.00$ & 0.70 & 0.830 \\
\hline RA-sustain & & & & 1 & $-.67 * * *$ & $.21 *$ & 2.47 & $1.00-4.00$ & 0.83 & 0.959 \\
\hline RA-denial & & & & & 1 & $-.23 *$ & 1.49 & $1.00-3.38$ & 0.62 & 0.945 \\
\hline RA-initiation & & & & & & 1 & 2.55 & $1.00-4.00$ & 0.76 & 0.900 \\
\hline
\end{tabular}

$* p<.05, * * p<.01, * * * p<.001$.

RA, relationship abuse; SA, sexual assault; sustain, sustainability.

to SA (e.g., Take Back the Night or similar campus community wide SA event), 17 questions were specific to RA (e.g., access to community-based domestic violence programs, including shelter services), and 14 questions were general for both SA and RA (SARA) (e.g., education programs for members of the Greek system, emergency call boxes on campus). In addition, our CCREM included perceptions of efforts, which we included for convergent validity purposes. We based all of the items included in the CCREM primarily on Karjane et al. (2002), our own expertise, and feedback from colleagues who are experts in campus SA and RA. Response options for each of the items were "Yes" (coded as 1), "No" (coded as 0 ), and "I do not know" (coded as missing). We created three summed scores, one for SA efforts, one for RA efforts, and one for combined SA and RA efforts; higher scores represent the presence of more efforts.

\section{Results}

\section{Analysis plan}

First, exploratory factor analyses (EFAs) were conducted separately for SA and RA items (i.e., one EFA for the SA items and one EFA for the RA items) because the items for SA and RA were identical and we wanted to avoid issues with item redundancy. Further, there is anecdotal evidence that campuses can be in different places regarding their intervention and prevention efforts, with some campuses further along in addressing SA than RA and research reviews document the greater attention to campus SA (Banyard 2014). After determining the subscales for SA (see Table 1) and RA (see Table 2) through the EFAs, we calculated in- ternal consistency reliabilities (see Table 3). Next, a correlation matrix was computed in order to examine potential correlates of the CCREM subscales (see Table 4). Next, interclass correlation coefficients and interrater reliabilities were calculated in order to determine the extent to which individuals within the same campus rated their campus similar. Finally, we calculated an average score for each of the participating campuses on the CCREM subscales in order to determine the overall campus variability in readiness.

\section{Factor structure and internal consistency reliabilities}

Sexual assault. An EFA was conducted with all of the SA items using principle axis factors and a promax rotation. Factor solutions were considered initially using a cutoff eigenvalue level of 1.00. Inspection of eigenvalues and scree plots indicated that a one-, two-, or three-factor solution could be appropriate solutions. Examination of these different solutions indicated that the three-factor solution provided the best fit to the data and made the most sense conceptually. We proceeded with factor analysis for the three-factor solution given that Bartlett's test of sphericity for the three-factor solution was significant, $\chi^{2}(1485)=6422.40, p<.001$, and the Kaiser-Meyer-Olkin measure of sampling adequacy was acceptable (.890).

The rotated three-factor solution accounted for a total of $45.17 \%$ of the variance. Items were required to have a primary factor loading of .45 or above in combination with no cross-loading greater than .35 on any factor; items that were correlated with one another at .80 or higher were examined, and the one that had the lowest corrected item-total correlation was removed to avoid item redundancy (Nunnally and Bernstein 1994; Tabachnick and Fidel 2001). Forty-five of

Table 4. Correlations Among CCREM Subscales and Other Theoretically Related Variables

\begin{tabular}{|c|c|c|c|c|c|c|}
\hline & SA-sustain & $S A-$ denial & SA-initiate & $R A-$ sustain & $R A-$ denial & $R A$-initiate \\
\hline Age & $.23 * *$ & $-.16^{*}$ & $-.19 * *$ & $.16^{*}$ & -.04 & -.15 \\
\hline Gender & $.19 *$ & -.07 & -.09 & $.16^{*}$ & -.04 & -.03 \\
\hline SA Vic & .03 & -.08 & .09 & -.04 & .05 & .07 \\
\hline SA Perp & .08 & $-.18 * *$ & -.04 & -.01 & -.07 & .01 \\
\hline RA Vic & .01 & -.07 & .03 & .08 & -.09 & .11 \\
\hline RA Perp & .13 & $-.19 * *$ & -.04 & .122 & -.12 & .02 \\
\hline SA efforts & $.71 * * *$ & $-.58 * * *$ & .13 & $.54 * * *$ & $-.60 * * *$ & .19 \\
\hline RA efforts & $.66^{* * *}$ & $-.47 * * *$ & .08 & $.76^{* * *}$ & $-.68 * * *$ & $-.54 * * *$ \\
\hline SA-RA efforts & $.60 * * *$ & $-.58 * * *$ & .10 & $.54 * * *$ & $-.54 * * *$ & .17 \\
\hline
\end{tabular}

$* p<.05, * * p<.01, * * * p<.001$.

Sustain, sustainability; Vic, victimization; Perp, perpetration. Gender $0=$ woman; gender $1=\operatorname{man}$. 
the original 55 items met criteria for simple structure within this sample and were retained in the solution. Factor loadings are presented in Table 1. Interpretation of the items loading on each factor led to the naming of factor 1, sustainability; factor 2, denial; and factor 3, initiation. Scores for the three factors were computed by averaging scores loading on each factor. Descriptive statistics, Cronbach's alpha, and correlations among the three factors are shown in Table 3. All of the subscales demonstrated acceptance internal consistency.

Relationship abuse. An EFA was conducted with all of the RA items using principle axis factors and a promax rotation using all of the criteria specified above for SA. Examination of these different solutions indicated that the three-factor solution provided the best fit to the data and made the most sense conceptually. We proceeded with factor analysis for the three-factor solution given that Bartlett's test of sphericity for the three-factor solution was significant, $\chi^{2}(1485)=7907.54, p<.001$, and the KaiserMeyer-Olkin measure of sampling adequacy was acceptable (.92). The rotated three-factor solution accounted for a total of $60.83 \%$ of the variance. Forty of the original 55 items met criteria for simple structure within this sample and were retained in the solution. Factor loadings are presented in Table 2. Interpretation of the items loading on each factor led to the naming of factor 1, sustainability; factor 2, denial; and factor 3 , initiation. Scores for the three factors were computed by averaging scores loading on each factor. Descriptive statistics, Cronbach's alpha, and correlations among the three factors are shown in Table 3. All of the subscales demonstrated acceptance internal consistency.

\section{Correlates of community readiness}

We conducted a series of Pearson's $r$ bivariate correlations and $t$-tests to determine the extent to which the CCREM subscales related to demographic variables, contact with SA and RA victims and perpetrators, and the presence or absence of SA and RA efforts, policies, and resources on campus (see Table 4). Results showed that older individuals reported higher SA and RA sustainability, less SA denial, and less SA initiation. Female participants reported greater levels of SA and RA sustainability than male participants. All other demographic correlations were nonsignificant. Similarly, exposure to SA and RA victims and perpetrators was largely unrelated to the different CCREM subscales with the exception of SA denial being inversely related to contact with SA and RA perpetrators. Finally, SA efforts, RA efforts, and SARA efforts were related in the expected directions with all CCREM subscales. Although not presented in this article due to length constrictions, university title/position was generally unrelated to perceptions of campus readiness to engage; however, it should be noted that the cell sizes were very small for a number of the positions.

We also conducted a series of dependent sample $t$-tests to compare readiness for SA to readiness for RA. Results suggested that RA denial was significantly higher than SA denial $[t(164)=2.40, p<.01]$, initiation SA was significantly higher than initiation RA $[t(164)=8.44, p<.001]$, and that sustainability SA was significantly higher than sustainability $\operatorname{RA}[t(145)=10.05, p<.001]$.

\section{Interrater reliability and intraclass correlation} coefficients

In order to examine the extent to which members of the same campus community rated their campuses similarly on the six different subscales of the CCREM, we calculated interrater reliability (IRR) and interclass correlation coefficients (ICC) for each of the six subscales. For these analyses, we only included individuals in which there were four or more respondents from their university, based on statistical expertise (personal communication). These analyses thus included 143 individuals from 25 different universities. The IRR and ICC values were as follows: SA sustainability $(\mathrm{IRR}=.67 ; \mathrm{ICC}=0.30) ; \mathrm{SA}$ denial $(\mathrm{IRR}=.47 ; \mathrm{ICC}=0.15)$; $\mathrm{SA}$ initiation $(\mathrm{IRR}=.68$; $\mathrm{ICC}=0.29)$; RA sustainability $(\mathrm{IRR}=.61 ; \mathrm{ICC}=0.24) ; \mathrm{RA}$ denial $(\mathrm{IRR}=.49 ; \mathrm{ICC}=0.18)$; and RA initiation $(\mathrm{IRR}=.81 ; \mathrm{ICC}=0.46)$. These $\mathrm{IRR}$ and ICC values indicate that there was fair to good agreement on the sustainability and initiations subscales and poor to fair agreement on the denial subscales (Cicchetti and Sparrow 1981; Fleiss 1981; Barrett 2001).

\section{Discussion}

In the current study, we described the development and preliminary psychometric evaluation of a quantitative measure to access campus community readiness to engage around issues of SA and RA grounded in the CRM (Plested et al. 2006). Factor analytic analyses resulted in separate three-factor structure for SA and for RA: sustainability, initiation, and denial with many of the same items in both of the SA and RA factors but with some different items, as well. This finding further supports the notion that readiness to address SA and RA, while similar, are indeed different in some ways, and that campuses are generally further along in addressing SA compared to RA. This is likely because there has been more focus on SA than on RA in the media and within state and federal governments.

It is noteworthy that although the CRM interview tool has six dimensions and nine stages of readiness, these dimensions and stages did not emerge in the CCREM factor structure. Rather, we found three stages of readiness (denial, initiation, sustainability) and the various dimensions (e.g., leadership, resources) hung together within the three separate readiness stages. These findings may be the result of several reasons. First, it may be hard for individuals to distinguish between more fine-tuned differences in the stages that the theory outlines. Rather, in practice, individuals may see more broad distinctions between a campus that is not at all engaged or working to initiate change, and a campus that has already done considerable work on the issue. It may also be the case, however, that our items were not clear enough in differentiating between or among the stages. Future research is needed to explore whether a simpler three-category scoring system provides enough information to campuses to assist in their change efforts. The variability we found among campuses as well as individuals within a campus on scores on the current measure suggests that it is a promising new measure.

In addition to a strong factor structure, the CCREM demonstrated good internal consistency. However, the IRR varied from poor to moderate, which could be for a number of reasons. First, individual perceptions certainly play a role, and we would expect that they would vary to some extent 
among respondents, even of the same community. Further, due to our methodology, we cannot be certain about what levels of expertise about their campus SA and RA efforts, policies, and initiations participants possessed. That is, although we instructed participants to indicate if they did not know the answer to a specific question, it is possible that some individuals, who may have not been informed enough to do so, were answering questions. Beyond campus community membership, other variables that impacted perceptions of readiness included age, gender, contact with SA perpetrators, and specific SA and RA efforts, policies, and initiations. However, many of the demographic and contact with SA and RA victim and perpetrator variables were unrelated to a number of subscales. Clearly, an area ripe for future investigation is to better understand the factors that impact perceptions of community readiness and the extent to which an actual overall community readiness score can be obtained. In other words, it remains an empirical question the extent to which the CCREM truly measures community norms, beliefs, attitudes, and infrastructures versus individual-level attitudes and knowledge. This too is a critical area of future investigation.

Despite some promising preliminary psychometric data, we also acknowledge that the current measure and study have some limitations that we would like to see improved in future research. First, regarding the execution of the data collection, we suggest that researchers create ways to ensure that only individuals with the necessary knowledge complete the CCREM, something we cannot guarantee was the case in this study. Second, we had only a few respondents per campus due to low response rates, which negatively impacts IRR and ICC (or alternatively even with more respondents per campus interrater agreement could still be low especially if individuals are reporting more on personal attitudes). Thus, we suggest that researchers come up with additional strategies that lead to a higher number of respondents from each campus with the ability to accurately answer the questions. Third, our respondents were from New England universities only, and thus we are unsure if our findings can be generalized to campus communities in other regions of the United States, especially those that are more diverse. Thus, future research should examine the psychometric properties and factor structure of the measure using a nationally representative sample of U.S. colleges and universities. Furthermore, adaptations may need to be made to the CCREM where cultural considerations that impact prevention and policy efforts may be especially important.

Additionally, more rigorous methodological approaches are needed to confirm the factor structures detected in the current study as well as the validity of the measure. A critical next step would be to obtain a nationally representative sample of colleges and universities so that a confirmatory factor analysis could be conducted to ensure that the factor structure is consistent and replicable. This would also allow for the creation of national normative data by which schools could use to interpret their score. There is also the need for future research to gather construct, convergent, divergent, concurrent, and predictive validity of the CCREM. Also, given the length of the measure, future research would also benefit working to create a psychometrically sound short version of the CCREM. Future research would also benefit from longitudinal methodologies to de- termine the measures' sensitivity in tracking change over time, especially with the implementation of new SA and RA efforts, initiatives, and policies.

\section{Conclusions}

The continued revision and refinement of the CCREM measure created and preliminarily evaluated in this study is notable in light of the increasing attention given to campus responses to SA and RA. Although we are still in the early stages of developing and evaluating the CCREM, we are hopeful that researchers and practitioners will join us in refining and improving the CCREM so that it can be an additional evidence-based assessment tool used in our efforts to improve campus responses to and prevention of SA and RA.

\section{Acknowledgments}

Funding for this project was provided by the University of New Hampshire's College of Liberal Arts Dean's Office.

We would like to thank all of the individuals who participated in this study, as well as Amaya Birk, Angela Neal, Meghan Craig, Ashley MacPherson, Alyssa Frechette, Kristin Lindemann, Michaela Salusi-Simpson, and Sidney Bennett for their assistance with participant recruitment and data collection. We would also like to thank Hong Chang for his statistical consultation, and Mary Mayhew and Mark Rubinstein for their feedback on drafts of the measures during the development stage. Finally, we would like to thank Linda Stanley for her continued guidance on the community readiness model and other facets of community-based research.

\section{Author Disclosure Statement}

No competing financial interests exist. Some of the data presented in this article were also presented at the 2014 International Family Violence Research Conference, Portsmouth, NH.

\section{References}

Banyard VL. (2014). Improving college campus-based prevention of violence against women: A strategic plan for research built on multipronged practices and policies. Trauma Violence Abuse. 15, 339-351.

Barrett P. (2001). Assessing the reliability of rating data-revised. Retrieved from www.pbarrett.net/presentations/rater.pdf

Basile KC, Saltzman LE. (2002). Sexual violence surveillance: Uniform definitions and recommended data elements version 1.0. (Centers for Disease Control and Prevention, National Center for Injury Prevention and Control, Atlanta, GA.) Retrieved from www.cdc.gov/ViolencePrevention/pub/SV_surveillance.html

Brackley M, Davilla Y, Thornton J, et al. (2003). Community readiness to prevent intimate partner violence in Bexar County Texas. J Transcult Nurs. 14, 227-236.

California Campus Sexual Assault Task Force. (2004). California campus blueprint to address sexual assault. Report to Governor and California Legislature. Retrieved from www.vawnet.org/Assoc Files_VAWnet/CampusBlueprint.pdf

Casey EA, Lindhorst TP. (2009). Toward a multi-level, ecological approach to the primary prevention of sexual assault: Prevention in peer and community contexts. Trauma Violence Abuse. 10, 91-114.

Cicchetti DV, Sparrow SS. (1981) Developing criteria for establishing the interrater reliability of specific items in a given inventory. Am J Ment Defic. 86, 127-137. 
DeWalt TA. (2009). The primary prevention of sexual violence against adolescents in Racine county and the community readiness model. Dissertations, 2009, Paper 12. Retrieved from http://epublications .marquette.edu/dissertations_mu/12/

Edwards KM, Sylaska KM, Barry JE, et al. (2015). Physical dating violence, sexual violence, and unwanted pursuit: A comparison of incidence rates among sexual minority and heterosexual college students. J Interpers Violence. 30, 580-600.

Findholt N. (2007). Application of the community readiness model for childhood obesity prevention. Publ Health Nurs. 24, 565-570.

Fisher BS, Cullen FT, Turner MG. (2000). The sexual victimization of college women (NCJ 182369). (National Institute of Justice, Washington, DC.)

Fleiss JL. (1981). Statistical Methods for Rates and Proportions, 2nd edition. (Wiley, New York, NY.)

Jumper-Thurman P, Vernon IS, Plested B. (2007). Advancing HIV/ AIDS prevention among American Indians through capacity building and the community readiness model. J Publ Health Manag Pract. 117, S96-S103.

Karjane HK, Fisher BS, Cullen FT. (2002). Campus Sexual Assault: How America's Institutions of Higher Education Respond. Final Report, NIJ Grant \# 1999-WA-VX-0008. (Education Development Center Inc., Newton, MA.)

Kilpatrick DG, Resnick HS, Ruggiero KJ, et al. (2007). Drugfacilitated, incapacitated, and forcible rape: A national study. Final Report, NIJ Grant \# 2005-WG-BX-0006. (Medical University of South Carolina, National Crime Victims Research and Treatment Center, Charleston, SC.)

Krebs CP, Lindquist CH, Warner TD, et al. (2007). The Campus Sexual Assault (CSA) Study. Grant Number 2004-WGBX-0010, awarded by the National Institute of Justice, Office of Justice Programs, U.S. Department of Justice. Retrieved from www.ncjrs.gov/ pdffiles1/nij/grants/221153.pdf

Lichty LF, Campbell R, Schuiteman J. (2008). Developing a universitywide institutional response to sexual assault and relationship violence. J Prev Interv Community. 36, 5-22.

Luna N. (2008). Clark County Dropout Needs Assessment Report: Community Readiness Data Collection Process to Address Latina/ Latino School Dropout. (Reno, NV: University of Nevada Cooperative Extension.)

Mikton C, Mehra R, Butchart A, et al. (2011). A multidimensional model for child maltreatment prevention readiness in low- and middle-income countries. J Community Psychol. 39, 826-843.

Mikton C, Power M, Raleva M, et al. (2013). The assessment of the readiness of five countries to implement child maltreatment pre- vention programs on a large scale. Child Abuse Negl. 37, 12371251.

Moynihan MM, Banyard VB, Cares AC, et al. (2015). Encouraging responses in sexual and relationship violence prevention: What program effects remain one year later? J Interpers Violence. 30, $110-132$.

Nunnally JC, Bernstein IH. (1994). Psychometric Theory, 3rd edition. (McGraw-Hill Inc., New York, NY.)

Plested BA, Edwards RW, Jumper-Thurman P. (2006, April). Community readiness: A handbook for successful change. (Tri-Ethnic Center for Prevention Research, Fort Collins, CO.)

Prochaska JO, DiClemente CC. (1983). Stages and processes of selfchange of smoking: Toward an integrative model of change. J Consult Clin Psychol. 51, 390-395.

Prochaska JO, DiClemente CC. (1984). Self change processes, selfefficacy and decisional balance across five stages of smoking cessation. Prog Clin Biol Res. 156, 131-140.

Raffle H. (2011). Selecting a community readiness tool. Document available at http://mha.ohio.gov/Portals/2/assets/SPF\%20Phases/ Assessment/5_Community_Readiness_Tools.pdf

Stallones L, Gibbs-Long J, Gabella B, et al. (2008). Community readiness and prevention of traumatic brain injury. Brain Inj. 22, 555-564.

Tabachnick BG, Fidel LS. (2001). Using Multivariate Statistics. (Allyn and Bacon, Boston, MA.)

U.S. Universities. (2014, June 30). Retrieved from the University of Texas at Austin website: www.utexas.edu/world/univ/alpha/

Wasco SM, Zadnik L. (2013). Assessing campus readiness for prevention: Supporting campuses in creating safe and respectful communities. (Pennsylvania Coalition Against Rape, Enola, PA.) Retrieved from www.pcar.org/sites/default/files/file/CampusWholeBook_Web.pdf

Whipple K, Simmons SJ, Caldwell R, et al. (2010). Assessing support for campus tobacco policy in tobacco country. Health Educ. 42, 3-11.

White House Task Force to Protect Students From Sexual Assault (U.S.). (2014). Not alone: The first report of the White House Task Force to protect students from sexual assault. Retrieved from http:// purl.fdlp.gov/GPO/gpo48344

Address correspondence to: Katie M. Edwards, PhD Department of Psychology University of New Hampshire 15 Academic Way Durham, NH 03824

E-mail: katie.edwards@unh.edu 